06;09

\title{
УФ-ассистирование процесса роста прозрачных проводящих слоев на основе оксида цинка
}

\author{
(C) А.Х. Абдуев ${ }^{1}$, А.Ш. Асваров ${ }^{1, \uparrow}$, А.К. Ахмедов ${ }^{1}$, Р.М. Эмиров ${ }^{2}$,
}

\section{В.В. Беляев ${ }^{3}$}

${ }^{1}$ Институт фризики им. Х.И. Амирханова ДагНЦ РАН, Махачкала

${ }^{2}$ Дагестанский государственный университет, Махачкала

${ }^{3}$ Московский государственный областной университет

๑ E-mail: cht-if-ran@mail.ru

Поступило в Редакцию 17 мая 2017 г.

Выполнены сравнительные исследования микроструктуры, оптических и электрических характеристик слоев $\mathrm{ZnO}$, легированного галлием, синтезированных методом магнетронного распыления при ассистировании процесса роста ультрафиолетовым излучением и без ассистирования. Обнаружено, что УФ-ассистирование процесса роста прозрачных проводящих слоев на основе $\mathrm{ZnO}$ способствует улучшению их электрических характеристик за счет создания дополнительных донорных центров и снижения рассеяния носителей заряда на межзеренных границах, существенно не влияя при этом на морфологию слоев и средний коэффициент оптического пропускания в видимой области спектра.

DOI: $10.21883 /$ PJTF.2017.22.45259.16874

Промышленное формирование прозрачных электродов для различных электронных устройств, как правило, предполагает магнетронный синтез прозрачных проводящих слоев на аморфных подложках при относительно низких температурах. При этом образуются поликристаллические слои с характерной столбчатой структурой и, как следствие, низкой подвижностью носителей заряда. В последние годы заметно активизировались исследования, направленные на разработку альтернативных материалов и технологий синтеза прозрачных электродов для различных приложений [1]. Заметное место в ряду этих исследований занимает поиск резервов для улучшения характеристик прозрачных проводящих слоев на основе доступного коммерчески привлекательного 


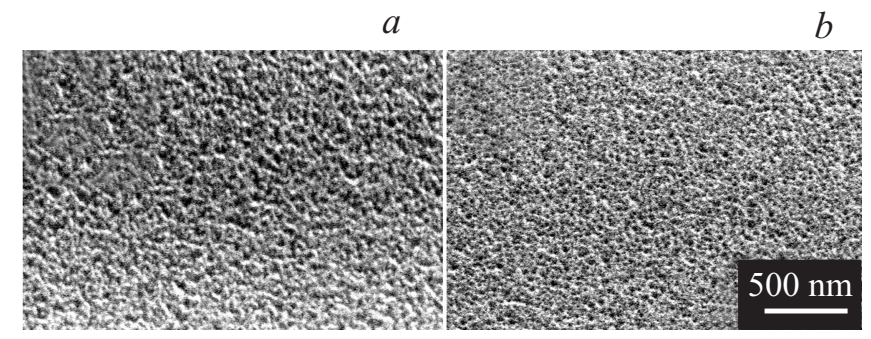

Рис. 1. Микрофотографии поверхности слоев $\mathrm{ZnO}: \mathrm{Ga}$, напыленных в условиях УФА при $60^{\circ} \mathrm{C}(a)$ и $250^{\circ} \mathrm{C}(b)$.

оксида цинка [2-4]. Таким резервом является, в частности, формирование структурно однородных слоев на основе оксида цинка из потока реагентов с избыточным содержанием паров металла [5,6], а также композиционных мишеней на основе системы $\mathrm{ZnO}: \mathrm{Ga}-\mathrm{C}$ [7].

Известно, что создание кислородных вакансий в слоях $\mathrm{ZnO}$ может быть достигнуто также в результате десорбции кислорода или фотолиза при УФ-облучении поверхности [8]. В работе [5] приведены результаты сравнительных исследований структуры и электрических свойств слоев, синтезированных в условиях избыточного давления паров Zn, а также слоев, полученных при ассистировании процесса роста УФ-излучением. Показано, что в обоих случаях формирование слоев протекает при избыточном содержании цинка на поверхности роста. В этих исследованиях осаждение велось на подложки, плоскость которых была перпендикулярна плоскости распыляемой мишени и не подвергалась бомбардировке отрицательными ионами кислорода. В работе [9] показано, что УФ-обработка слоев, полученных золь-гельметодом, приводит к снижению их удельного сопротивления, а также существенно влияет на морфологию формируемых слоев.

В настоящей работе изучены характеристики слоев $\mathrm{ZnO}$, легированного галлием (далее, $\mathrm{ZnO}: \mathrm{Ga}$ ), осажденных методом магнетронного распыления на постоянном токе на подложки, которые многократно проходили над плоскостью распыляемой керамической мишени, т.е. специальных мер по предотвращению нежелательной ионной бомбардировки не предпринималось. Выполнены сравнительные исследования микроструктуры, оптических и электрических характеристик слоев

Письма в ЖТФ, 2017, том 43, вып. 22 

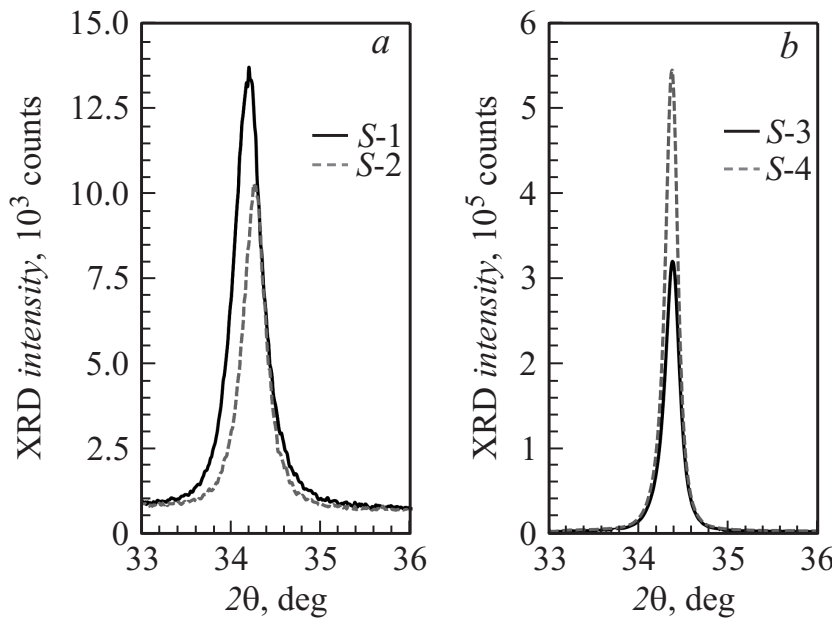

Рис. 2. Профили XRD-рефлекса $(002) \mathrm{ZnO}$ для слоев $\mathrm{ZnO}: \mathrm{Ga}$, напыленных при $60(a)$ и $250^{\circ}(b)$.

$\mathrm{ZnO}: \mathrm{Ga}$, синтезированных при ассистировании процесса роста ультрафиолетовым излучением и без ассистирования.

Синтез слоев осуществлялся методом магнетронного распыления на постоянном токе керамической мишени $\mathrm{ZnO}: \mathrm{Ga}$ с уровнем легирования галлием 3 at.\% (ОАО „Полема“, Тула) в атмосфере $\operatorname{Ar}(99.999 \%)$ (распылительная установка „Магнетрон“, Воткинск). Предварительно очищенные подложки (предметное стекло СП-7102) устанавливались на вращающемся металлическом барабане, косвенный нагрев которого до требуемой температуры осуществлялся с помощью трубчатых инфракрасных ламп. Для ультрафиолетового ассистирования (УФА) процесса роста слоев использовалась ртутная лампа ДРТ-240, расположенная сразу за магнетронным распылительным узлом по направлению вращения барабана. Перед каждым циклом осаждения слоев проводилось предварительное распыление мишени на заслонку в течение $10 \mathrm{~min}$. Время осаждения и ток магнетронного разряда для всех слоев были одинаковыми и составляли $120 \mathrm{~min}$ и $100 \mathrm{~mA}$ соответственно. В проведенном эксперименте было установлено, что при распылении мишени в режиме стабилизации тока напряжение разряда зависит от 
Таблица 1. Интенсивность $I$, угловое положение $2 \theta$, ширина на половине высоты $\beta$ рефлекса (002) $\mathrm{ZnO}$, рассчитанные параметр решетки и размер области когерентного рассеяния D

\begin{tabular}{c|c|c|c|c|c}
\hline Номер образца & $I$, counts & $2 \theta, \mathrm{deg}$ & $\beta, \mathrm{deg}$ & $c, \mathrm{~nm}$ & $D, \mathrm{~nm}$ \\
\hline$S-1$ & 12602 & 34.18 & 0.384 & 0.5242 & 20 \\
$S-2$ & 9261 & 34.25 & 0.312 & 0.5232 & 25 \\
$S-3$ & 305022 & 34.38 & 0.190 & 0.5213 & 53 \\
$S-4$ & 528394 & 34.37 & 0.170 & 0.5214 & 64
\end{tabular}

того, включен или нет источник УФ-излучения внутри распылительной камеры. При включенной УФ-лампе напряжение разряда после десятиминутной „тренировки“ устанавливалось на уровне $325 \mathrm{~V}$, тогда как при распылении мишени в обычных условиях (без УФА) напряжение разряда стабилизировалось на уровне $310 \mathrm{~V}$. Рост напряжения разряда при включении УФ-лампы может быть обусловлен дополнительным фотостимулированным ростом поверхностного дефицита кислорода в области зоны эрозии распыляемой мишени [8]. В настоящей работе было синтезировано четыре набора тонкопленочных образцов $\mathrm{ZnO}: \mathrm{Ga}$ толщиной $d \approx 250 \mathrm{~nm}$ : два при температуре $T_{s u b}=60^{\circ} \mathrm{C}$ (образцы $S-1$ и $S-2)$ и два при температуре $T_{s u b}=250^{\circ} \mathrm{C}$ (образцы $S-3$ и $\left.S-4\right)$. При этом образцы $S-4$ и $S-2$ были получены в условиях УФА.

Исследования морфологии синтезированных слоев (с помощью растрового электронного микроскопа SEM Leo-1450, Carl Zeiss) показали, что все четыре образца характеризуются мелкозернистой структурой с малым рельефом поверхности. При этом существенных различий в морфологии для слоев, напыленных в условиях УФА и без него, не наблюдалось. Морфология поверхности в большей степени зависит от температуры роста слоев. Как можно видеть из рис. 1, на котором представлены микрофотографии поверхности слоев $\mathrm{ZnO}: \mathrm{Ga}$, синтезированных при УФ процесса роста, с увеличением температуры подложки наблюдается сглаживание рельефа поверхности формируемой пленки. Исследование поперечных сколов полученных слоев показало, что при увеличении температуры $T_{s u b}$ до $250^{\circ} \mathrm{C}$ структура слоев становится более упорядоченной, в результате чего формируются более плотные и гладкие слои.

Письма в ЖТФ, 2017, том 43, вып. 22 


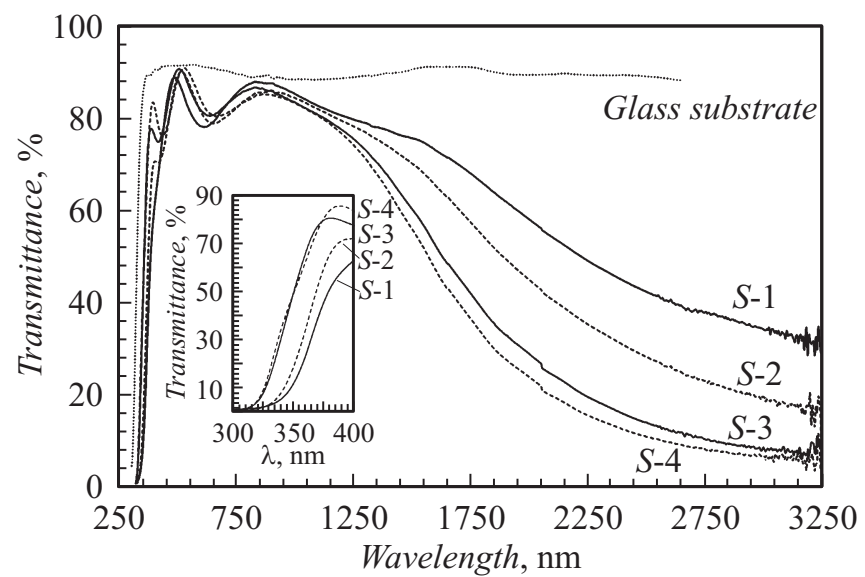

Рис. 3. Спектры пропускания слоев $\mathrm{ZnO}: \mathrm{Ga}$, напыленных при $60250^{\circ} \mathrm{C}$ без $(S-1$ и $S-3)$ и с УФА $(S-2$ и $S-4)$. На вставке - область краевого поглощения спектров пропускания слоев $\mathrm{ZnO}: \mathrm{Ga}$ после вычета вклада подложки.

Рентгеноструктурный анализ слоев (дифрактометр Empyrean, PANalytical B.V.) показал, что синтезированные поликристаллические слои имеют аксиальную текстуру с ориентацией оси $c$ кристаллитов по нормали к поверхности. При температуре подложки $T_{\text {sub }}=60^{\circ} \mathrm{C}$ УФ-ассистирование процесса роста приводило к снижению интенсивности доминирующего рефлекса $(002) \mathrm{ZnO}$ и его сдвигу в сторону больших углов $2 \theta$ (рис. 2, $a$ ), что свидетельствует о формировании внутри кристаллитов значительного количества статических микроискажений (атомов внедрения и/или вакансий) и снижении сжимающих макронапряжений в слое при УФА.

Нагрев подложек до $T_{\text {sub }}=250^{\circ} \mathrm{C}$ способствовал формированию более совершенных слоев (рис. $2, b$ ). Как видно из рис. 2 и табл. 1 , с ростом температуры подложки наблюдаются увеличение интенсивности рефлекса (002) более чем на порядок величины, заметное уменьшение его ширины на половине высоты и дальнейший сдвиг его местоположения в сторону больших углов. При этом УФА вносит дополнительный вклад в рост кристаллического совершенства формируемых слоев: интенсивность рефлекса (002) вырастет примерно в 2 раза, а рассчитанный размер области когерентного рассеяния $D-$ более чем на $20 \%$. 
Таблица 2. Оптические (средний коэффициент пропускания $T^{*}$ в видимой области спектра $(380-780 \mathrm{~nm})$, оптическая ширина запрещенной зоны $E_{g}$, показатель преломления $n$ на длине волны $\lambda=500 \mathrm{~nm}$ ) и электрические (удельное сопротивление $\rho$, концентрация свободных носителей $N$ и холловская подвижность $\mu$ ) характеристики синтезированных слоев

\begin{tabular}{c|c|c|c|c|c|c}
\hline $\begin{array}{c}\text { Номер } \\
\text { образца }\end{array}$ & $T, \%$ & $E_{g}, \mathrm{eV}$ & $n_{500 \mathrm{~nm}}$ & $\begin{array}{c}\rho, \\
10^{-4} \Omega \cdot \mathrm{cm}\end{array}$ & $\begin{array}{c}N, \\
10^{20} \mathrm{~cm}^{-3}\end{array}$ & $\mu, \mathrm{cm}^{2} \cdot \mathrm{V}^{-1} \cdot \mathrm{s}^{-1}$ \\
\hline$S-1$ & 81.0 & 3.27 & 2.00 & 53.1 & 2.9 & 4.0 \\
$S-2$ & 80.4 & 3.35 & 2.02 & 24.7 & 4.7 & 5.3 \\
$S-3$ & 83.4 & 3.52 & 1.95 & 5.94 & 7.7 & 13.8 \\
$S-4$ & 83.3 & 3.59 & 1.97 & 4.56 & 8.6 & 15.9
\end{tabular}

* Суммарный коэффициент пропускания слоя $\mathrm{Zn}$ : Ga и стеклянной подложки.

Спектры пропускания слоев, осажденных на стеклянные подложки, приведены на рис. 3 (спектрофотометр UV-3600, Shimadzu). Bce образцы характеризуются относительно высоким коэффициентом пропускания в видимой области спектра $(T>80 \%)$ и резким краем поглощения, расположенным в УФ-области. Наличие интерференционных полос в видимой области и значения максимумов интерференции, близких к коэффициенту пропускания подложки, свидетельствуют об отсутствии потерь, связанных с поглощением и рассеянием света в слоях и на их границах. С увеличением температуры роста и при УФА в спектрах наблюдается сдвиг края поглощения в коротковолновую область спектра (вставка на рис. 3), который коррелирует со снижением оптического пропускания в ближней инфракрасной области $(800-3250 \mathrm{~nm})$.

Приведенные в табл. 2 данные по оптическим характеристикам показывают, что УФА процесса роста приводит к увеличению оптической ширины запрещенной зоны $E_{g}$ с сохранением высокой прозрачности в видимой области. Более высокие значения показателя преломления $n$, наблюдаемые в слоях $S-2$ и $S$-4 (по сравнению с образцами $S-1$ и $S-3$ ), можно объяснить отклонением от стехиометрии в соответствующих слоях под воздействием УФ. В работе [10] отмечалось, что слои $\mathrm{ZnO}$ с составом, близким к стехиометрическому, имели более низкий показатель преломления.

Письма в ЖТФ, 2017, том 43, вып. 22 
Результаты структурных и оптических исследований синтезированных слоев $\mathrm{ZnO}: \mathrm{Ga}$ находятся в хорошем согласии с данными, полученными при изучении их электрических характеристик, которые также приведены в табл. 2. УФА при температурах подложки 60 и $250^{\circ} \mathrm{C}$ приводит к снижению удельного сопротивления слоев $\mathrm{ZnO}: \mathrm{Ga}$ за счет роста и концентрации, и подвижности свободных носителей заряда.

Увеличение концентрации носителей заряда обусловлено образованием дополнительных донорных центров (кислородных вакансий) в результате УФА. Рост концентрации свободных электронов приводит к наблюдаемому увеличению ширины запрещенной зоны в силу эффекта Бурштейна-Мосса.

В свою очередь увеличение холловской подвижности коррелирует с результатами структурных исследований, которые выявили увеличение размера области когерентного рассеяния $D$ при УФА. Увеличение $D$ влечет за собой уменьшение рассеяния носителей заряда на межзеренных границах.

Таким образом, показано, что УФ-ассистирование процесса магнетронного роста способствует улучшению функциональных характеристик прозрачных проводящих слоев на основе оксида цинка. Мы полагаем, что рост структурного совершенства слоев $\mathrm{ZnO}: \mathrm{Ga}$, наблюдаемый при УФ-ассистировании процесса осаждения, обусловлен тем, что при УФА включается механизм роста, предложенный в ранних работах [6,7] и связанный с формированием на поверхности роста „динамической“ нестехиометричной фазы $\mathrm{ZnO}_{1-x}$.

Работа выполнена с использованием оборудования Аналитического центра коллективного пользования ДагНЦ РАН и при финансовой поддержке РФФИ в рамках научных проектов № 16-07-00503 и 16-0700469.

\section{Список литературы}

[1] Stadler A. // Materials 2012. V. 5. P. 661.

[2] Abduev A., Akmedov A., Asvarov A. et al. // Plasma Process. Polym. 2015. V. 12. P. 725 .

[3] Horwat D., Mickan M., Chamorro W. // Phys. Status Solidi C. 2016. V. 13. P. 951.

[4] Tien Ch.-L., Yu K.-Ch., Tsai T.-Y. et al. // Appl. Surf. Sci. 2015. V. 354. P. 79. 
[5] Tominaga K., Umezu N., Mori I. et al. // Thin Solid Films. 1998. V. 316. P. 85.

[6] Abduev A., Akhmedov A., Asvarov A. // J. Phys.: Conf. Ser. 2011. V. 291. P. 012039.

[7] Абдуев А.Х., Ахмедов А.К., Асваров А.Ш. // Письма в ЖТФ. 2014. Т. 40. B. 14. C. 71.

[8] Morrison S.R. The chemical physics of surfaces. N.Y.-London: 1977. 415 p. [Моррисон С. Химическая физика поверхности твердого тела. М.: Мир, 1980, $488 \mathrm{c}$.

[9] Tseng Y.-K., Pai F.-M., Chen Y.-Ch. et al. // Electron. Mater. Lett. 2013. V. 9. P. 771.

[10] Достанко А.П., Агеев О.А., Голосов Д.А. и др. // ФТП. 2014. Т. 48. В. 9. C. 1274 . 